СТАТЬИ

УДК $630 * 232.22$

СРАВНИТЕЛЬНЫЕ РЕЗУЛЬТАТЫ ИСПОЛЬЗОВАНИЯ СЕЯНЦЕВ СОСНЫ ОБЫКНОВЕННОЙ С ОТКРЫТОЙ И ЗАКРЫТОЙ КОРНЕВОЙ СИСТЕМОЙ ПРИ ИСКУССТВЕННОМ ЛЕСОВОССТАНОВЛЕНИИ В УСЛОВИЯХ ЗАПАДНОГО ЗАБАЙКАЛЬЯ

Гладинов А.Н., Коновалова Е.В., Содбоева С.Ч.

ФГБОУ ВО «Бурятская государственная сельскохозяйственная академия им. В.Р. Филиппова», Улан-Удэ, e-mail: gladinov@mail.ru

В статье рассматриваются результаты исследования особенностей использования сеянцев сосны обыкновенной с закрытой (ЗКС) и открытой корневой системой (ОКС) при искусственном лесовосстановлении в природных условиях Западного Забайкалья. Актуальность темы обусловлена необходимостью перехода от использования посадочного материала с ОКС к посадочному материалу с ЗКС. Переход к использованию посадочного материала с ЗКС подразумевает решение многих вопросов, связанных как с выращиванием сеянцев, так и с отработкой технологии их посадки, которая должна быть приближена к особенностям природных условий района посадок. Несоответствие технологий выращивания и посадки сеянцев местным природным условиям может привести к отрицательным результатам. В ходе исследования проведена оценка приживаемости лесных культур, созданных разными видами сеянцев, а также определены их биометрические показатели. Результаты исследования показали, что согласно проценту приживаемости лесные культуры, созданные обоими видами сеянцев, нуждаются в дополнении. При этом приживаемость у сеянцев с ЗКС оказалась выше, чем у сеянцев с ОКС. Приживаемость сеянцев с ЗКС составляет $69 \%$, приживаемость с ОКС $-59,8 \%$. Хотя, по сведениям некоторых авторов, приживаемость сеянцев с ЗКС может достигать $100 \%$. Визуальный осмотр сеянцев в рядах на лесокультурной площади показал отсутствие годового прироста у сеянцев с ЗКС и закручивание главного корня из-за его неправильного развития в ячейке кассеты. По биометрическим показателям (высота, масса, диаметр шейки ствола) сеянцы с ОКС значительно опережают сеянцы с ЗКС. Все это указывает на необходимость проведения дальнейших исследований особенностей применения сеянцев с ЗКС при искусственном лесовосстановлении в условиях Западного Забайкалья.

Ключевые слова: искусственное лесовосстановление, сеянцы сосны обыкновенной, закрытая и открытая корневая система, сравнительные результаты, Западное Забайкалье

\title{
RESULTS OF A COMPARATIVE ANALYSIS OF THE USE OF SCOTTAL PINE SEEDLINGS WITH OPEN AND CLOSED ROOT SYSTEM UNDER ARTIFICIAL FOREST RECOVERY IN THE CONDITIONS OF WESTERN TRANSBAIKALIE
}

Gladinov A.N., Konovalova E.V., Sodboeva S.Ch.

Buryat State Akademy of Agriculture named V.R. Filippov, Ulan-Ude, e-mail: gladinov@mail.ru

The article discusses the results of a study of the peculiarities of using Scots pine seedlings with closed (CRS) and open root systems (ORS) during artificial reforestation in the natural conditions of Western Transbaikalie. The relevance of the topic is due to the need to switch from using planting material with ORS to planting material with CRS. The transition to the use of planting material with CRS implies the solution of many issues related to both the cultivation of seedlings and the development of their planting technology, which should be close to the peculiarities of the natural conditions of the planting area. Inconsistency of technologies for growing and planting seedlings to local natural conditions can lead to negative results. In the course of the study, an assessment of the survival rate of forest cultures created by different types of seedlings was carried out, as well as their biometric indicators were determined. The results of the study showed that, according to the survival rate, forest cultures created by both types of seedlings need to be supplemented. At the same time, the survival rate in seedlings with CRS was higher than in seedlings with ORS. The survival rate of seedlings with CRS is $69 \%$, the survival rate of seedlings with ORS is $59.8 \%$. Although, according to some authors, the survival rate of seedlings with CRS can reach $100 \%$. Visual inspection of seedlings in rows on a silvicultural area showed the absence of annual growth in seedlings with CRS and twisting of the main root due to its abnormal development in the cell of the cassette. In terms of biometric parameters (height, weight, trunk neck diameter), seedlings with ORS are significantly ahead of seedlings with CRS. All this indicates the need for further research on the features of the use of seedlings with CRS in artificial reforestation in the conditions of Western Transbaikalie.

Keywords: artificial reforestation, Scots pine seedlings, closed and open root system, comparative results, Western Transbaikalie

Традиционно искусственное лесовосстановление сеянцами сосны обыкновенной в условиях Западного Забайкалья проводится посадочным материалом с открытой корневой системой. В данном случае технология лесовосстановления отработана годами. Сеянцы выращиваются в питомниках и вы- саживаются под меч Колесова по нарезанным плугом ПКЛ-70 бороздам. Приживаемость, за редким исключением, достаточно высока. Однако процесс посадки сеянцев с ОКС ограничен по времени - это весна сразу после схода снега и до наступления раннелетней засухи, а также осень. Если 
не уложиться в оптимальные по климатическим условиям сроки посадки сеянцев, результат приживаемости культур может оказаться низким. В отличие от ОКС сеянцы с ЗКС можно высаживать в течение всего вегетационного периода. Это увеличивает потенциальные площади, на которых может быть проведено лесовосстановление в течение одного сезона $[1,2]$.

Согласно новым требованиям с 1 января 2022 г. 20\% посадочного материала, используемого при лесовосстановлении, должно быть с закрытой корневой системой (ЗКС) [3]. Это требует, во-первых, отработки технологии выращивания сеянцев с ЗКС кассетным способом в условиях закрытого грунта. Во-вторых, отработки посадки сеянцев с ЗКС, с обеспечением высокой приживаемости и сохранности в разнообразных и достаточно суровых почвенно-климатических условиях районов Западного Забайкалья. Исследований по определению эффективности лесовосстановления с использованием сеянцев сосны обыкновенной с ЗКС в условиях Западного Забайкалья еще не проводилось.

Теоретически применение ЗКС должно дать лучшие результаты по приживаемости, чем ОКС, так как корни сеянца в данном случае заключены в ком плодородной земли, защищающей их от иссушения и обеспечивающей элементами питания. Однако на практике результаты могут оказаться неоднозначными. Согласно отзывам многочисленных авторов, технология выращивания и посадки сеянцев сосны обыкновенной с закрытой корневой системой имеет ряд особенностей, которые необходимо учитывать. Это и размер ячейки кассеты (в первую очередь высота ячейки, которая влияет на правильность формирования корня), и состав применяемого почвогрунта, и своевременность подкормки удобрениями. Большое значение имеют природно-климатические условия и особенности посадки сеянца [4, 5]. Все это напрямую влияет на приживаемость и дальнейшую сохранность сеянцев с ЗКС. Простой перенос западных технологий посадки сеянцев с ЗКС может не дать положительных результатов [6, с. 15]. При несоответствии технологии производства лесных культур сеянцами с ЗКС местным природным условиям результат может оказаться хуже, чем с традиционным использованием сеянцев с ОКС, о чем имеются сообщения ряда авторов. Это делает актуальным проведение сравнительного исследования использования сеянцев с ЗКС и ОКС при искусственном лесовосстановлении.
Цель исследования - определить эффективность и особенности использования сеянцев сосны обыкновенной с открытой и закрытой корневой системой при искусственном лесовосстановлении в условиях Западного Забайкалья.

\section{Материалы и методы исследования}

Объектом исследования являются лесные культуры сосны обыкновенной, созданные сеянцами с ОКС и ЗКС, выращенными в условиях закрытого грунта. Сеянцы с ОКС выращивались в грядках с ручным десятистрочным посевом. Сеянцы с ЗКС выращивались в кассетах с высотой ячейки 8 см. В теплицах обеспечивался соответствующий микроклимат.

Посадки проводились в сентябре 2020 г. на площади 40,2 га в квартале 189 Илькинского участкового лесничества Заиграевского лесничества Республики Бурятия. Территория лесничества относится к Байкальскому горному лесному району Южно-Сибирской горной лесорастительной зоны. Главная порода - сосна обыкновенная, лесные культуры - сплошные. Лесокультурная площадь представлена гарями десятилетней давности. Подготовка почвы (нарезка борозд) проводилась тракторами ТЛ-5АЛМ-01 и МТ3-82 с плугом ПКЛ-70. Размещение борозд равномерное с расстоянием между бороздами 3,5 м, шаг посадки с ОКС - 0,7 м., с ЗКС - 1 м. Сеянцы с ОКС высаживались под меч Колесова, с ЗКС при помощи посадочной трубы.

Климат района исследования резко континентальный, с суровой и продолжительной зимой, большой среднегодовой и среднесуточной амплитудой колебания температур. Средняя температура января $-25^{\circ} \mathrm{C}$ (абс. мин. $\left.-46,8^{\circ} \mathrm{C}\right)$. Устойчивый снежный покров образуется во второй половине ноября и местами достигает 15-20 см. Таяние снежного покрова происходит во второй половине марта начале апреля. Весенний период (апрель май) характеризуется сильными ветрами, малооблачной погодой с положительными температурами днем и возможными заморозками ночью. В конце мая - июне наблюдается самая низкая относительная влажность воздуха в течение года и минимальное количество осадков. Высокие дневные температуры, наличие в это время года сильных ветров в сочетании с недостаточным количеством осадков приводит к сильному иссушению почвы. Лето теплое, в первой половине засушливое, во второй - дождливое. Средняя температура июля выше $+18^{\circ} \mathrm{C}$ (абс. макс. 
$\left.+36,8^{\circ} \mathrm{C}\right)$. Наибольшее количество осадков выпадает в летнее время (август). Годовое количество осадков - 241 мм [7, с. 3]. Осень сухая, с малооблачной погодой, днем тепло, в ночное время возможны ранние заморозки (конец августа - начало сентября).

Почвы в районе исследования супесчаные, легкого мехсостава, подверженные ветровой и водной эрозии, с маломощным гумусовым горизонтом. Дно борозд представлено легкими суглинками.

\section{Результаты исследования и их обсуждение}

В течение первых двух лет критерием оценки успешности проведенного тем или иным способом процесса лесовосстановления является приживаемость, определяемая как отношение числа посадочных мест с живыми растениями к общему числу посадочных мест на лесокультурной площади. Оценка приживаемости проводилась согласно ГОСТ с заложением учетных отрезков.

Приживаемость сеянцев определялась закладкой учетных отрезков общей площадью 0,84 га на лесокультурных участках с сеянцами ЗКС и ОКС. Анализ результатов показал, что приживаемость сеянцев с ЗКС составляет 69\%, приживаемость с ОКС $59,8 \%$. Исходя из полученных значений приживаемости, данные посадки требуют дополнения. В то же время по некоторым литературным источникам приживаемость сеянцев с ЗКС может достигать $100 \%$.

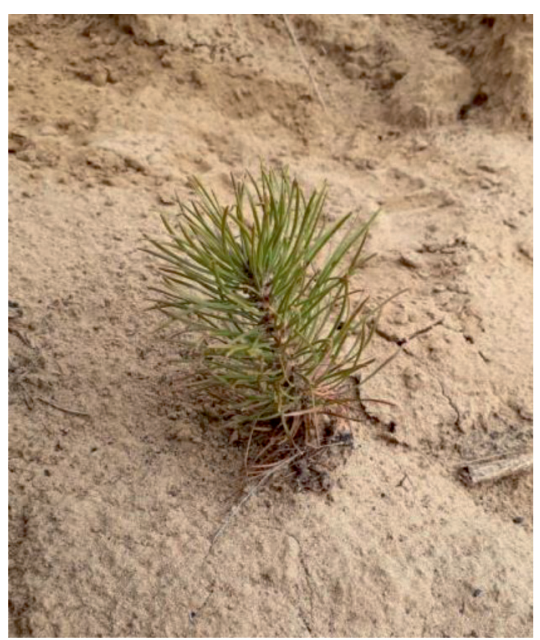

Рис. 1. Сеянеи сосны обыкновенной с 3 КС

Внешний осмотр показывает неудовлетворительные результаты. У сеянцев с ЗКС не наблюдается годового прироста (рис. 1), при этом верхушечная почка заложена. На момент исследования они имеют почти такие же размеры, как и при посадке. Кроме того, визуальный осмотр показал, что у сеянцев не наблюдается роста главного корня.

При выкопке сеянцев, после разрушения прикорневого кома торфяного субстрата было обнаружено закручивание главного корня (рис. 2). Несмотря на то, что приживаемость у сеянцев с ЗКС выше, чем у сеянцев с ОКС, дальнейшее развитие данных растений находится под вопросом.

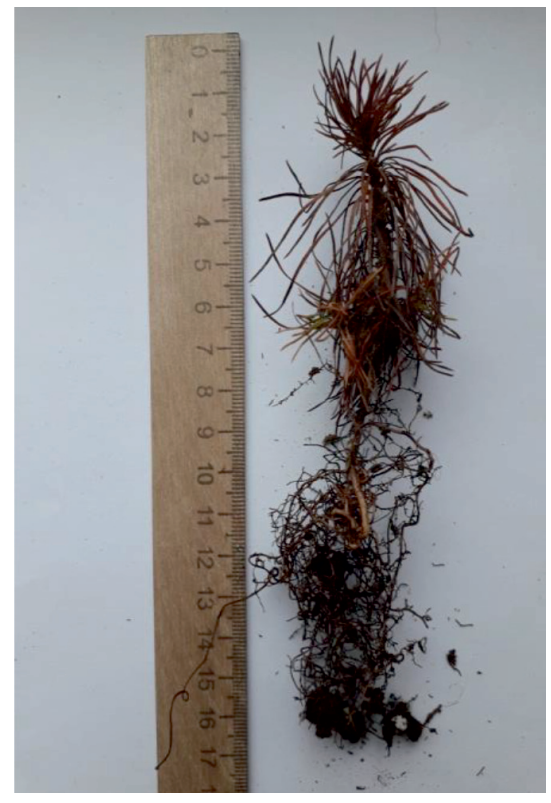

Рис. 2. Корневая система сеяниа соснь обыкновенной с ЗКС

Первоначально торфяной субстрат обеспечивает хорошую приживаемость, но, находясь в верхнем пересохшем слое почвы, при высыхании он может перестать пропускать капиллярную влагу. Этому способствует недостаточное количество осадков в момент высаживания сеянцев. Кроме того, закрученный главный корень остается в верхнем (20 см) слое почвы и не достигает глубоко расположенных влагообеспеченных слоев. Плохая влагообеспеченность в дальнейшем может увеличить отпад сеянцев.

В отличие от сеянцев с ЗКС сеянцы с ОКС имеют хорошо развитый главный корень, обеспечивающий растения влагой из более глубоко расположенных влажных суглинистых слоев почвы (рис. 3). В перспективе это обеспечит хорошую сохранность растений, однако в первый год у сеянцев с ОКС наблюдался большой отпад. 


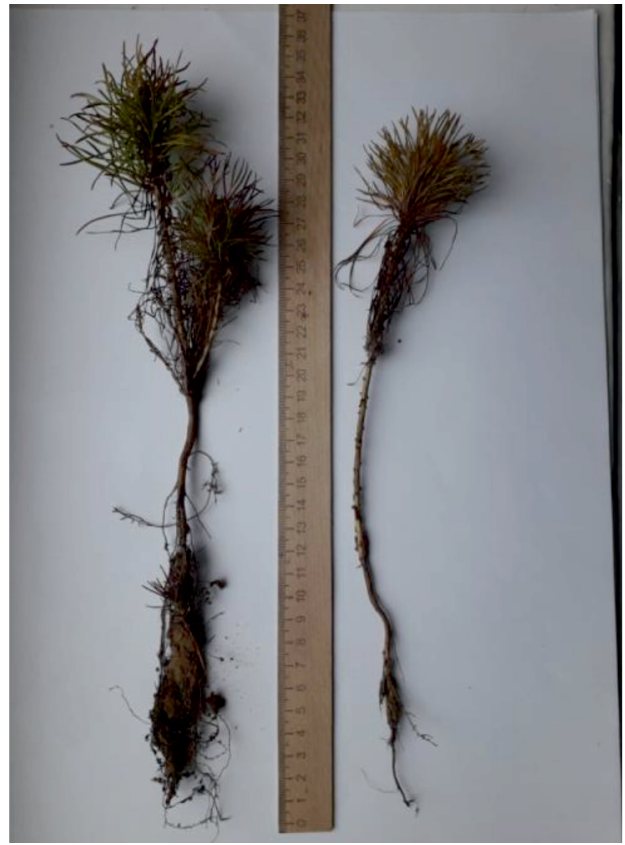

Рис. 3. Корневая система сеянцев сосны обыкновенной с ОКС

Наличие отдельных рядов с большим количеством погибших растений может указывать на нарушение технологии посадки. Кроме того, наблюдается замывание дна посадочных борозд слоем песка, который несут потоки воды, так как земли на лесокультурных площадях склоновые, эрозионно опасные. Соответственно, выше

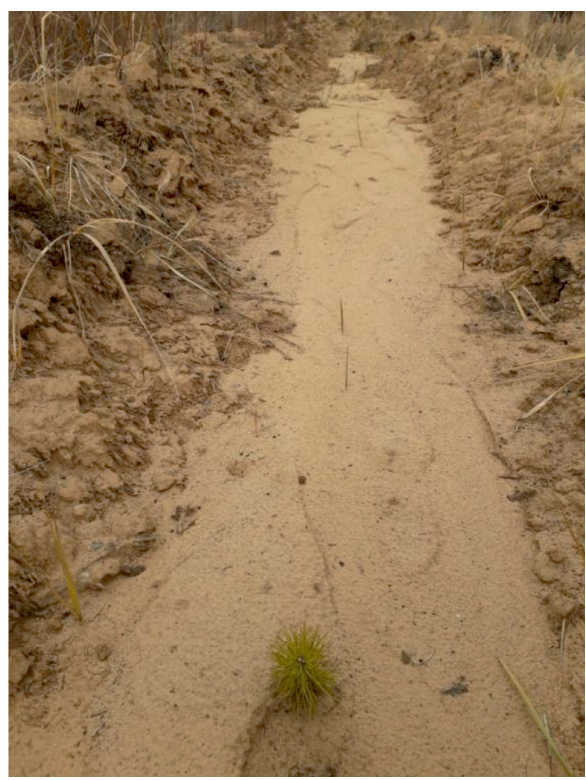

по склону наблюдается размывание дна борозд (рис. 4). Большой отпад сеянцев с ОКС зафиксирован именно в таких рядах.

Также в ходе исследования определялись биометрические показатели сеянцев: масса сеянца, диаметр прикорневой шейки ствола, высота сеянца, длина хвои и воздушно-сухой вес сеянцев (таблица).

Такие показатели, как масса и диаметр прикорневой шейки ствола, у сеянцев с ОКС в 2 раза превышают такие же показатели у сеянцев с ЗКС. Высота сеянцев с ОКС также почти в два раза превышает высоту сеянцев с ЗКС. Это различие было заложено изначально, так как сеянцы с ОКС в теплице росли в условиях конкуренции, что приводило к их вытягиванию. Сеянцы с ЗКС росли одиночно в ячейках кассеты, не испытывая конкуренции. В дальнейшем это различие усугубляется нормальным развитием корневой системы у сеянцев с ОКС, чего нельзя сказать о сеянцах с ЗКС. При этом длина хвои почти одинаковая, с превышением у ЗКС: 3,6 (ОКС) и 4,1 (ЗКС) см.

\section{Биометрические показатели сеянцев} с ОКС и ЗКС

\begin{tabular}{|l|c|c|}
\hline \multicolumn{1}{|c|}{ Показатели } & Сеянец с ОКС & Сеянец с ЗКС \\
\hline Масса & $2,48 \pm 0,51$ г & $1,04 \pm 0,48$ г \\
\hline Диаметр шейки & $3,3 \pm 0,06 \mathrm{MM}$ & $1,5 \pm 0,03 \mathrm{мм}$ \\
\hline Высота & $20,3 \pm 0,18 \mathrm{~cm}$ & $11,5 \pm 0,12 \mathrm{~cm}$ \\
\hline Длина хвои & $3,6 \pm 0,02 \mathrm{~cm}$ & $4,1 \pm 0,03 \mathrm{~cm}$ \\
\hline
\end{tabular}

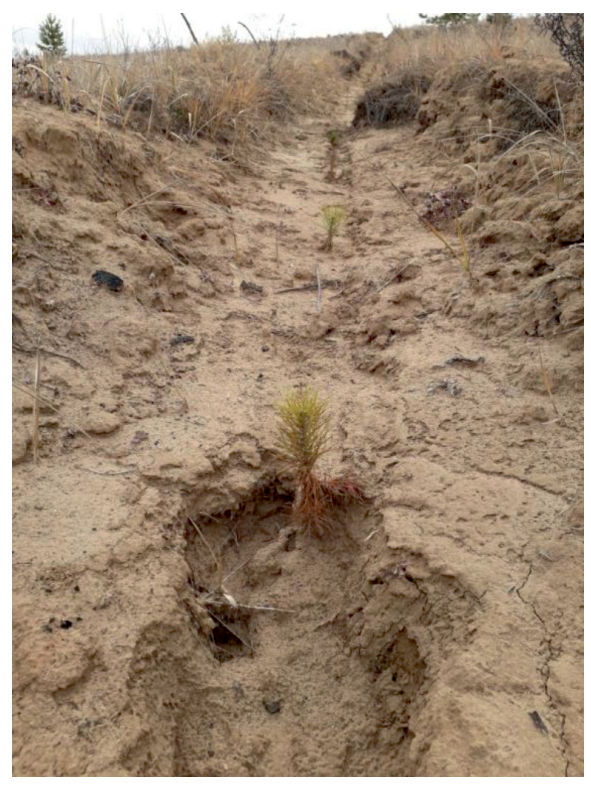

Рис. 4. Последствия водной эрозии. Ряды сеянцев с ОКС 
Таким образом, при гораздо более высоких показателях приживаемости сеянцы с ЗКС по биометрическим показателям значительно уступают сеянцам с ОКС. В дальнейшем сеянцы с ОКС могут показать более высокие темпы прироста, выдерживая конкуренцию с травянистой растительностью. Этому будет способствовать и нормально сформировавшаяся корневая система. Сеянцы с ЗКС, вероятно, будут отставать в своем развитии и в последующий год могут увеличить процент отпада из-за неправильно сформировавшейся корневой системы, так как закрученный главный корень не достигнет влагообеспеченных слоев почвы. Это требует дополнительных наблюдений с целью установления особенностей дальнейшего развития сеянцев с ЗКС в условиях Западного Забайкалья.

По результатам данного исследования можно указать на необходимость обеспечения правильного формирования главного корня у сеянцев с ЗКС, для чего следует использовать кассеты с более высокой ячейкой - до 11 см (при условии обеспечения нормального заглубления при посадке посадочной трубой). Следует также избегать высаживать сеянцы с ЗКС в засушливые периоды года (май - июнь), в противном случае пересохший ком торфяного субстрата не будет пропускать влагу. С целью устранения данного недостатка торфяной ком следует засыпать слоем почвы толщиной 1-2 см и плотно обжимать. У сеянцев с ОКС основной причиной отпада чаще всего бывает несоблюдение технологии посадки (образование воздушного кармана в прикорневой зоне и изгиб главного корня) наряду с использованием неодревесневшего посадочного материала, на что также следует обращать особое внимание.

\section{Заключение}

Проведенные исследования показали, что приживаемость сеянцев сосны обыкновенной, как с ОКС, так и с ЗКС, на искусственно восстанавливаемой лесокультурной площади попадает в интервал 25-85\%, т.е. лесные культуры требуют дополнения. При этом приживаемость у сеянцев с ЗКС на 9,2\% выше, чем у сеянцев с ОКС. В данном случае более высокая приживаемость у сеянцев с ЗКС обеспечена наличием торфяного субстрата, богатого питательными элементами. В то же время большой отпад сеянцев с ОКС может быть обусловлен нарушением технологии посадки, а также последствиями водной эрозии почв.
Почти по всем биометрическим показателям (кроме длины хвои) сеянцы с ОКС опережают сеянцы с ЗКС примерно в два раза. По визуальным наблюдениям у сеянцев с ЗКС отсутствует годовой прирост, хотя верхушечная почка сформирована. Осмотр корней показал, что у сеянцев с ЗКС главный корень закручен из-за неправильного развития в ограниченном пространстве ячейки кассеты. В дальнейшем это может привести к увеличению отпада сеянцев с ЗКС, так как главный корень не растет вниз, а остается в поверхностном слое, где ощущается недостаток почвенной влаги. Это требует дальнейшего проведения исследований по установлению особенностей использования сеянцев сосны обыкновенной с ЗКС в условиях Западного Забайкалья, а также корректировке технологии их выращивания в условиях закрытого грунта и посадки на лесокультурных площадях.

\section{Список литературы / References}

1. Гоф А.А., Жигулин Е.В., Залесов С.В. Причины низкой приживаемости сеянцев сосны обыкновенной с закрытой корневой системой в ленточных борах Алтая // Успехи современного естествознания. 2019. № 12-1. С. 9-13.

Gof A.A., Zhigulin E.V., Zalesov S.V. The reasons for the low survival rate of Scots pine seedlings with a closed root system in the ribbon forests of Altai // Uspekhi sovremennogo yestestvoznaniya. 2019. № 12-1. P. 9-13 (in Russian).

2. Носников В.В. ЗКС: за и против // Лесное и охотничье хозяйство. 2008. № 4. [Электронный ресурс]. URL: https://elib.belstu.by/bitstream/123456789/25497/1/Nosnikov ZKS.pdf (дата обращения: 16.10.2021).

Nosnikov V.V. ZKS: pros and cons // Lesnoye i okhotnich'ye khozyaystvo. 2008. № 4. [Electronic resource]. URL: https://elib. belstu.by/bitstream/123456789/25497/1/Nosnikov_ZKS.pdf (date of access: 16.10.2021) (in Russian).

3. Приказ Министерства природных ресурсов и экологии Российской Федерации от 4 декабря 2020 года № 1014 «Об утверждении Правил лесовосстановления, состава проекта лесовосстановления, порядка разработки проекта лесовосстановления и внесения в него изменений». [Электронный ресурс]. URL: https://docs.cntd.ru/ document/573123762 (дата обращения: 14.10.2021).

Order Ministry of Natural Resources and Environment of the Russian Federation dated December 4, 2020 No. 1014 «On approval of the Rules for reforestation, the composition of the reforestation project, the procedure for the development of the reforestation project and amendments to it». [Electronic resource]. URL: https://docs.cntd.ru/document/573123762 (date of access: 14.10.2021). (in Russian).

4. Бобринев В.П., Пак Л.Н. Эффективность выращивания лесных культур крупномерным посадочным материалом в Восточном Забайкалье // Известия ОГАУ. 2016. № 2 (58). C. $40-42$.

Bobrinev V.P., Pak L.N. The efficiency of growing forest crops with large-sized planting material in eastern Transbaikalie // Izvestiya OGAU. 2016. № 2 (58). P. 40-42 (in Russian)

5. Гоф А.А., Жигулин Е.В., Залесов С.В., Оплетаев А.С. Опыт создания лесных культур сеянцами с закрытой корневой системой на гарях Алтайского края // Международный научно-исследовательский журнал. 2019. № 12 (90). Ч. 2. [Электронный pecypc]. URL: http://research-journal.org/ agriculture/opyt-sozdaniya-lesnyx-kultur-seyancami-s-zakrytojkornevoj-sistemoj-na-garyax-altajskogo-kraya/ (дата обращения: 16.10.2021). 
Gouf A.A., Zhigulin E.V., Zalesov S.V., Opletaev A.S. Experience in the creation of forest cultures by seedlings with a closed root system in the burnt-out areas of the Altai Territory // Mezhdunarodnyy nauchno-issledovatel'skiy zhurnal. 2019 № 12 (90). Part 2 [Electronic resource]. URL: http://researchjournal.org/agriculture/opyt-sozdaniya-lesnyx-kulturseyancami-s-zakrytoj-kornevoj-sistemoj-na-garyax-altajskogokraya/ (date of access: 16.10.2021) (in Russian).

6. Грибов C.Е., Ганжа Н.В. Лесоводственно-экономическая оценка лесных культур, созданных различным видом посадочного материала // Молочнохозяйственный вестник. 2015. № 1 (17). [Электронный ресурc]. URL: https:// molochnoe.ru/journal/sites/molochnoe.ru.journal/files/jrnl publication/17-1-book-v1.pdf (дата обращения: 16.10.2021).

Gribov S.E., Ganzha N.V. Silvicultural and economic assessment of forest cultures created by various types of planting material // Molochnokhozyaystvennyy vestnik. 2015. № 1 (17). [Electronic resource]. URL: https://cyberleninka.ru/ article/n/lesovodstvenno-ekonomicheskaya-otsenka-lesnyhkultur-sozdannyh-razlichnym-vidom-posadochnogo-materiala (date of access: 16.10.2021) (in Russian).

7. Заиграевский район. Схема территориального планирования. Том IV. Мероприятия по сохранению равновесия экологической среды. Пояснительная записка. Улан-Удэ, 2008. [Электронный ресурc]. URL: https:/fgistp.economy.gov. ru/ais/of1?id=3AE7E0F5FF7E3C4D99A6E4E575837F05 (дата обращения: 14.10.2021).

Zaigraevsky area. Spatial planning scheme. Volume IV. Measures to maintain the balance of the ecological environment. Explanatory note. Ulan-Ude, 2008. [Electronic resource]. URL: https://fgistp.economy.gov.ru/ais/of1?id=3AE7E0F5FF7E3C4D 99A6E4E575837F05 (date of access: 14.10.2021) (in Russian). 